\title{
Reliable detection of Trisomy 21 using MALDI-TOF mass spectrometry
}

Dorothy J. Huang, $M D^{1}$, Matthew R. Nelson, $P h D^{2}$, Bernhard Zimmermann, $P h D^{1}$, Lech Dudarewicz, MD, $P h D^{3}$, Friedel Wenzel ${ }^{4}$, Roland Spiegel, MD, MSc ${ }^{5}$, Balint Nagy, PhD ${ }^{6}$, Wolfgang Holzgreve, MD, MSc ${ }^{1}$, and Sinuhe Hahn, $P h D^{1}$

\begin{abstract}
Purpose: Current diagnostic methods for chromosomal abnormalities rely mainly on karyotyping and occasionally fluorescent in situ hybridization or quantitative polymerase chain reaction. We describe an alternative molecular method for the detection of trisomy 21 involving mass spectrometric analysis of single nucleotide polymorphisms.

Methods: In collaboration with Sequenom, Inc., 350 blinded amniotic fluid, amniocyte culture, chorionic villus, or amniotic fluid supernatant samples were analyzed for trisomy 21 using SNP analysis and matrix-assisted laser desorption/ionization time-of-flight (MALDI-TOF) mass spectrometry. Peak ratios were calculated for heterozygous genotypes and compared to control values generated from known euploid samples. An analytical algorithm using standard deviations from control values was used to determine the probability of a sample being affected or unaffected. Results: Seventy-three trisomy 21 samples from among the 350 blinded samples were correctly identified. There were no false-positive or false-negative results among the complete trisomy 21 samples. One sample exhibiting mosaicism for trisomy 21 was identified as being unaffected. Conclusions: MALDI-TOF mass spectrometry is a robust and reproducible method for the detection of trisomy 21 . Its amenability to highthroughput analysis and high degree of multiplexing make it a potential future diagnostic tool for the detection of other aneuploidies as well. Genet Med 2006:8(11):728-734.
\end{abstract}

Key Words: MALDI-TOF mass spectrometry, trisomy 21, aneuploidy, prenatal diagnosis, SNP

Although chromosomal abnormalities have been associated with up to $50 \%$ of all clinically recognized pregnancy losses, those involving chromosomes 13, 18, 21, $\mathrm{X}$ and $\mathrm{Y}$ are compatible with life and are of special concern. ${ }^{1}$ The most common of these, Down syndrome, is most often due to trisomy of chromosome 21. However, even duplications only involving the Down syndrome Critical Region (DSCR) of chromosome 21 may result in the clinical syndrome. ${ }^{2}$ Diagnostic methods rely on invasive techniques such as chorionic villus sampling (CVS) or amniocentesis, followed by culturing of fetal cells and karyotyping. ${ }^{3,4}$ However, results with this method can take up to two weeks to obtain, a delay which may cause significant parental anxiety. Failure of cell culture results in the need to repeat the invasive procedure or reliance on other methods of

From the ${ }^{1}$ Laboratory for Prenatal Medicine University Women's Hospital, Department of Research Spitalstrasse 21, CH4031 Basel, Switzerland; ${ }^{2}$ Sequenom, Inc., 3595 John Hopkins Court, San Diego, California 92121; ${ }^{3}$ Department of Medical Genetics Polish Mother's Memorial Hospital, Research Institute 281/289 Rzgowska Street, 93-338 Lodz, Poland; ${ }^{4}$ University Children's Hospital Postfach, CH4005 Basel, Switzerland; ${ }^{5}$ Human Genetics Laboratory, Genetica Weinbergstrasse 9, CH8001 Zürich, Switzerland; and ${ }^{6} 1^{\text {st }}$ Department of Obstetrics and Gynecology, Semmelweis University, Baross u. 27, Budapest H-1088, Hungary.

Sinuhe Hahn, PhD, Laboratory for Prenatal Medicine, University Women's Hospital, Department of Research, Spitalstrasse 21, CH4031 Basel, Switzerland.

Submitted for publication May 29, 2006.

Accepted for publication August 16, 2006.

DOI: 10.1097/01.gim.0000245573.42908.34 diagnosis. Another disadvantage is that smaller, partial chromosome duplications may not be observable by karyotyping.

Other methods aside from karyotyping are currently in use or are being developed. ${ }^{5} \mathrm{~A}$ widely used method is fluorescence in situ hybridization (FISH), which is reliable and accurate, but is labor intensive and requires intact cells. A rapidly developing molecular method for detection of abnormalities in chromosome number makes use of microarray-based comparative genomic hybridization (array CGH) analysis. ${ }^{6}$ Array CGH has been recently shown to be able to detect abnormalities in chromosome number, including trisomy 13, 18 and 21 and monosomy X, from cell-free DNA from amniotic fluid supernatant as well as single cells. ${ }^{7-9}$

Extensive work has been performed on molecular methods making use of frequently occurring genetic loci such as short tandem repeats (STR) or single nucleotide polymorphisms (SNP) to analyze chromosome number. One method which is currently being used in some European countries is quantitative fluorescent polymerase chain reaction (QF-PCR) analysis of STRs. Identification of aneuploidies involving chromosomes 13, 18, 21, X and Y has been demonstrated using this method. ${ }^{10-14}$ SNPs occur in the genome even more frequently than STRs, with on average one SNP found per kilobase. ${ }^{15}$ Melting curve analysis of SNPs using amniotic fluid cell cultures has been shown to be able to distinguish between trisomic and normal samples for chromosome 21. ${ }^{16,17}$ 
Matrix-assisted laser desorption/ionization time-of-flight (MALDI-TOF) mass spectrometry analysis of SNPs has also been explored as an alternative diagnostic technique to karyotyping. MALDI-TOF mass spectrometry has the advantages of capability for high-throughput analysis and the potential for high degrees of multiplexing, up to 24 assays in one reaction using the iPLEX ${ }^{\mathrm{TM}}$ system developed recently by Sequenom. ${ }^{18}$ PCR-based, allele-specific primer extension reactions performed just adjacent to a heterozygous SNP, such as in the homogenous MassEXTEND ${ }^{\circledR}$ procedure (Sequenom), followed by comparison of the peak areas generated on mass spectrum by the two products, allows for semiquantitative analysis of the gene of interest. This method can be applied to prenatal detection of abnormalities in chromosome number, as well as partial duplication of chromosomes. This approach for the detection of trisomy 21 was evaluated by researchers at Sequenom using assays for SNPs located on chromosome 21, the results from which were presented at the June 2005 American College of Medical Genetics (ACMG) meeting. ${ }^{19}$ DNA samples from 4 Down syndrome cell lines and 96 chorionic villus samples, of which 25 were trisomy 21 , were analyzed. These preliminary results demonstrated $93 \%$ sensitivity and $100 \%$ specificity for the method. In a separate study, Tsui et al. described similar approach using 13 trisomy 21 placental samples and nine trisomy 21 CVS samples..$^{20}$ Here, in collaboration with Sequenom and continuing the advances begun there, we report a large-scale evaluation of this technology for the detection of trisomy 21 using a wide variety of clinical samples. Additionally, we describe an analytical algorithm which is easy to use and interpret, and has potential applicability for actual clinical use.

\section{MATERIALS AND METHODS}

A variety of clinical samples of fetal origin from several institutions were obtained for this study. These included 120 crude amniotic fluid samples (Department of Medical Genetics, Polish Mother's Memorial Hospital, Lodz, Poland) or DNA extracted from crude amniotic fluid samples ( $1^{\text {st }}$ Department of Obstetrics and Gynecology, Semmelweis University, Budapest, Hungary), 75 acellular amniotic fluid supernatants (Department of Medical Genetics, Polish Mother's Memorial Hospital, Lodz, Poland), 40 amniocyte cultures (Department of Medical Genetics, University Children's Hospital, Basel, Switzerland) and DNA from 115 chorionic villus samples (Human Genetics Laboratory, Genetica, Zürich, Switzerland), taken at the usual gestational ages during which these procedures are performed (late first trimester for CVS, early- to midsecond trimester for amniotic fluid samples). Among these samples were both karyotypically normal and abnormal cases, which included not only trisomy 21 samples, but other chromosomal abnormalities as well. All samples were analyzed at the Laboratory for Prenatal Medicine in Basel by a single researcher (D.J.H.). The sample providers, who selected the cases to be evaluated, were uninvolved in the subsequent analyses. The identity of each sample and the number of abnormal sam- ples present were blinded to the researcher performing the analyses. Institutional Review Board approval was obtained at all sites.

\section{DNA extraction}

In cases where unextracted samples were obtained from participating institutions, DNA extraction was performed in our laboratory using the MagNA Pure LC Instrument (Roche Applied Science) and Roche MagNA Pure LC DNA IsolationLarge Volume kit. This included 100 crude amniotic fluid samples (Poland), the amniotic fluid supernatant samples (Poland) and the amniocyte culture samples (Basel, Switzerland). The amniotic fluid supernatant samples had been first centrifuged at $200 \times \mathrm{g}$ for 10 minutes to separate the cells from the supernatant. Immediately prior to DNA extraction, the supernatants were centrifuged at $16000 \times \mathrm{g}$ for 5 minutes to ensure removal of any remaining cellular material, thus leaving behind only the cell-free DNA-rich supernatant. For all the DNA extractions performed in our laboratory, $1000 \mu \mathrm{L}$ of starting material were extracted into a $200-\mu$ L elution volume according to the manufacturer's instructions. The DNA was then stored at $4^{\circ} \mathrm{C}$ until further use. All other samples in this study were processed at their respective institutions, which included 20 uncultured amniotic fluid samples from Hungary using the High Pure PCR Template Preparation Kit (Roche Diagnostics) and the 115 chorionic villus samples from Zürich, Switzerland using the Biorobot EZ1 Workstation and EZ1 DNA blood kit or EZ1 DNA tissue kit (Qiagen) according to the manufacturers' protocols.

\section{SNP Selection and assay design}

SNP selection and assay design were performed at Sequenom, Inc. SNPs located between the DSCR1 (Down syndrome Critical Region 1) and SIM2 (single-minded 2) genes on chromosome 21 were selected using existing HapMap data. For use in determining chromosome ratios, markers needed to be present in the heterozygous (informative) state; therefore, only SNPs with minor allele frequencies close to 0.5 were considered (Table 1). These were additionally narrowed down to 23 distantly spaced SNPs with pairwise linkage disequilibrium of $<0.3$, so that the genotypes observed across SNPs would be approximately independent. SNPs were chosen with regard primarily to heterozygote frequency in a Caucasian population, but which were also fairly polymorphic in other racial groups.

Multiplex assays were designed using the MassARRAY ${ }^{\circledR}$ Assay Design software (version 2.0.7.0). Assays were assessed for their performance regarding signal intensities, assay failure rates, tightness of clustering of heterozygotes in a normal population sample, consistency with Hardy-Weinberg proportions, and reproducibility. For our study, we selected 11 of these assays, grouped into two tetraplex reactions and one triplex reaction. Analysis of 11 SNPs was calculated to give an approximately $99 \%$ likelihood of observing at least 2 informative SNPs. These assays had been selected from a panel of assays initially tested at Sequenom using fibroblast and leukocyte 
Table 1

Allele frequencies of SNPs on chromosome 21 in the Caucasian population

\begin{tabular}{lccc}
\hline $\begin{array}{c}\text { SNP Accession } \\
\text { Number }\end{array}$ & Position & Alleles & $\begin{array}{c}\text { Minor Allele } \\
\text { Frequency }\end{array}$ \\
\hline rs11700664 & 22364226 & $\mathrm{~A} / \mathrm{G}$ & 0.45 \\
rs1475840 & 35200812 & $\mathrm{~A} / \mathrm{G}$ & 0.48 \\
rs170183 & 36770204 & $\mathrm{~A} / \mathrm{G}$ & 0.48 \\
rs18922600 & 34931166 & $\mathrm{C} / \mathrm{T}$ & 0.46 \\
rs2003624 & 35897343 & $\mathrm{C} / \mathrm{G}$ & 0.46 \\
rs2835336 & 36631509 & $\mathrm{~A} / \mathrm{G}$ & 0.45 \\
rs2835349 & 36735984 & $\mathrm{C} / \mathrm{T}$ & 0.47 \\
rs2850104 & 22851756 & $\mathrm{~A} / \mathrm{C}$ & 0.48 \\
rs432137 & 36875057 & $\mathrm{~A} / \mathrm{G}$ & 0.48 \\
rs732569 & 21411672 & $\mathrm{C} / \mathrm{T}$ & 0.50 \\
rs8127732 & 21057583 & $\mathrm{C} / \mathrm{T}$ & 0.48 \\
\hline
\end{tabular}

lines from 2 subjects with trisomy 21 and compared to normal controls, followed by further evaluation on 96 chorionic villus samples. ${ }^{19}$

\section{MassARRAY}

Amplification was performed using a minimum of $2 \mathrm{ng}$ of DNA per reaction. PCR was carried out in reaction volumes of $25 \mu \mathrm{L}$ except in the cases where amniotic fluid supernatants were tested, which were carried out in $50-\mu \mathrm{L}$ volumes due to the lower concentration of DNA and the increased amount of sample volume needed. Each reaction also contained $100 \mathrm{nM}$ each of the forward and reverse primer mixtures (Sequenom/ Microsynth) (Table 2), $3.5 \mathrm{mM} \mathrm{MgCl} 2$ (Applied Biosystems), $250 \mu \mathrm{M}$ each of dATP, dCTP, dGTP and dTTP (Invitrogen), $1 \times$ PCR Gold Buffer (Applied Biosystems) and 1 U AmpliTaq Gold Polymerase (Applied Biosystems). Amplification was performed for $10 \mathrm{~min}$ at $95^{\circ} \mathrm{C}$, followed by 45 cycles of $20 \mathrm{~s}$ at $95^{\circ} \mathrm{C}, 30$ s at $56^{\circ} \mathrm{C}$ and $1 \mathrm{~min}$ at $72^{\circ} \mathrm{C}$, then finally $5 \mathrm{~min}$ at $72^{\circ} \mathrm{C}$.

Following amplification, $10 \mu \mathrm{L}$ of each PCR reaction were transferred to a new plate using the Multimek 96 Automated 96-Channel Pipettor (Beckman) and subsequently treated with shrimp alkaline phosphatase (Sequenom). The reactions each included $0.6 \mu \mathrm{L}$ of shrimp alkaline phosphatase and $0.34 \mu$ L MassARRAY ${ }^{\circledR}$ Homogenous MassEXTEND ${ }^{\circledR}$ (hME) buffer (Sequenom). Incubation was performed at $37^{\circ} \mathrm{C}$ for 20 min, followed by $5 \mathrm{~min}$ at $85^{\circ} \mathrm{C}$.

Using primers annealing directly adjacent to the SNPs of interest, hME primer extension was performed. To the PCR products, $4 \mu \mathrm{L}$ of hME reaction mixture were added, which contained $600 \mathrm{nM}$ of one of three different extension primer mixes (Sequenom/Microsynth) (Table 2), $1.28 \mathrm{U}$ Thermosequenase (Sequenom) and either MassEXTEND ${ }^{\circledR}$ Mix 25 Tri (containing $50 \mu \mathrm{M}$ each of ddATP, ddCTP, ddGTP and dTTP) or MassEXTEND ${ }^{\circledR}$ Mix 26 Tri (containing $50 \mu \mathrm{M}$ each of ddATP, ddCTP, ddTTP and dGTP) (Sequenom). The reac-

Table 2

Amplification and hME extension primers grouped by assay plex

\begin{tabular}{|c|c|c|c|c|c|}
\hline Plex ID & MassExtend $\mathrm{Mix}^{a}$ & SNP ID & Forward Primer $^{b}$ & Reverse Primer ${ }^{b}$ & hME Extension Primer ${ }^{b}$ \\
\hline \multirow[t]{4}{*}{ TRI-N1648M } & \multirow[t]{4}{*}{26 Tri } & rs2003624 & $\begin{array}{l}\text { ACGTTGGATGCAAAGGTGAC } \\
\text { TTCCTCTCTG }\end{array}$ & $\begin{array}{l}\text { ACGTTGGATGAGGGACCT } \\
\text { GATCAGTTTCTC }\end{array}$ & TGCTTAAAGCCTGGGAG \\
\hline & & rs732569 & $\begin{array}{l}\text { ACGTTGGATGTCTTCCC } \\
\text { AGTAGAAGTGAGC }\end{array}$ & $\begin{array}{l}\text { ACGTTGGATGATTTACT } \\
\text { GATGTGCCGGGTG }\end{array}$ & $\begin{array}{l}\text { GATGCTGAGGATGAAAA } \\
\text { AT }\end{array}$ \\
\hline & & rs2850104 & $\begin{array}{l}\text { ACGTTGGATGGAAGGA } \\
\text { TTGACTGGTCTCAG }\end{array}$ & $\begin{array}{l}\text { ACGTTGGATGTTTTTC } \\
\text { CAGAGGTAATTGAC }\end{array}$ & $\begin{array}{l}\text { AGAGGTAATTGACAATTG } \\
\text { CTTT }\end{array}$ \\
\hline & & rs11700664 & $\begin{array}{l}\text { ACGTTGGATGCCTAAAAC } \\
\text { AGCACTGTCCAG }\end{array}$ & $\begin{array}{l}\text { ACGTTGGATGCAATGTGG } \\
\text { CTCCTAGAAAGC }\end{array}$ & $\begin{array}{l}\text { CCTAGAAAGCTTAATGG } \\
\text { TAC }\end{array}$ \\
\hline \multirow[t]{3}{*}{ TRI-N1649M } & \multirow[t]{3}{*}{25 Tri } & rs8127732 & $\begin{array}{l}\text { ACGTTGGATGTGGATGTA } \\
\text { GCATGTGCATGG }\end{array}$ & $\begin{array}{l}\text { ACGTTGGATGCACAAGCA } \\
\text { CACTCACATACG }\end{array}$ & $\begin{array}{l}\text { GTGCACACACCAATGTA } \\
\text { GG }\end{array}$ \\
\hline & & rs2835349 & $\begin{array}{l}\text { ACGTTGGATGGAAGGCAA } \\
\text { GAACTTCTTCAC }\end{array}$ & $\begin{array}{l}\text { ACGTTGGATGCAAGCATC } \\
\text { ACAAGATGAGCC }\end{array}$ & $\begin{array}{l}\text { CCACCGCCTTTTCTA } \\
\text { AT }\end{array}$ \\
\hline & & rs432137 & $\begin{array}{l}\text { ACGTTGGATGGTTCACAA } \\
\text { TCCGTCTCTGTC }\end{array}$ & $\begin{array}{l}\text { ACGTTGGATGGCTAAGCC } \\
\text { TCCTTGTTTGAC }\end{array}$ & $\begin{array}{l}\text { GGTCCTGGTAACCAC } \\
\text { AC }\end{array}$ \\
\hline \multirow[t]{4}{*}{ TRI-N1650M } & \multirow[t]{4}{*}{26 Tri } & rs 1892600 & $\begin{array}{l}\text { ACGTTGGATGAAGGCTT } \\
\text { ATAATGGTCCCC }\end{array}$ & $\begin{array}{l}\text { ACGTTGGATGAAAGCAG } \\
\text { GCAAGTCCAGCAC }\end{array}$ & $\begin{array}{l}\text { CCAGCACAGGCTGGT } \\
\text { AA }\end{array}$ \\
\hline & & rs 1475840 & $\begin{array}{l}\text { ACGTTGGATGGGGAAAG } \\
\text { TCATTGTCTATGAA }\end{array}$ & $\begin{array}{l}\text { ACGTTGGATGGTGCACA } \\
\text { GAGTAGACAATCT }\end{array}$ & $\begin{array}{l}\text { GCACAGAGTAGACAATCT } \\
\text { TTGAATT }\end{array}$ \\
\hline & & rs2835336 & $\begin{array}{l}\text { ACGTTGGATGAAACCTA } \\
\text { CCACTTTGTTGGG }\end{array}$ & $\begin{array}{l}\text { ACGTTGGATGGAGTATA } \\
\text { ACCCATGCTTCCG }\end{array}$ & $\begin{array}{l}\text { TTGTTGGGAGTAACTTTT } \\
\text { AGA }\end{array}$ \\
\hline & & rs 170183 & $\begin{array}{l}\text { ACGTTGGATGTCAGGAG } \\
\text { ATCCCAAAGAGAG }\end{array}$ & $\begin{array}{l}\text { ACGTTGGATGGCTTTAA } \\
\text { AGAGTCCAAAACGG }\end{array}$ & $\begin{array}{l}\text { CAAAACGGTTTAACAG } \\
\text { AGA }\end{array}$ \\
\hline
\end{tabular}

\footnotetext{
${ }^{a}$ MassEXTEND mix “26 Tri” contains ddATP, ddCTP, ddTTP and dGTP; MassEXTEND mix "25 Tri” contains ddATP, ddCTP, ddGTP and dTTP

${ }^{b}$ Primers are indicated in $5^{\prime} \rightarrow 3^{\prime}$ direction.
} 
tions were then initiated at $94^{\circ} \mathrm{C}$ for $2 \mathrm{~min}$, followed by 55 cycles of $94^{\circ} \mathrm{C}$ for $5 \mathrm{~s}, 52^{\circ} \mathrm{C}$ for $5 \mathrm{~s}$ and $72^{\circ} \mathrm{C}$ for $5 \mathrm{~s}$. Removal of salts was performed by adding $32 \mu \mathrm{L}$ of water and $6 \mathrm{mg}$ of Clean Resin (Sequenom) to each reaction, followed by gentle rotation of the plate for $10 \mathrm{~min}$ to mix. The samples were then centrifuged at $550 \times \mathrm{g}$ for $5 \mathrm{~min}$ and spotted onto a SpectroCHIP ${ }^{\circledR}$ (Sequenom) using a MassARRAY® Nanodispenser (Sequenom/Samsung). 3-Oligo Calibrant Mix (Sequenom) containing oligonucleotides with expected masses of 5044.4 D, 8486.6 D and 9977.6 D was also spotted onto each chip as a reference. Mass spectrometric analysis was then performed using the MassARRAY ${ }^{\circledR}$ Compact Analyzer (Bruker), and the data imported to and analyzed with the MassARRAY ${ }^{\circledR}$ Typer software (Sequenom). Positive and negative control samples were run on each chip. Allele frequencies for each assay were calculated using the MassARRAY ${ }^{\circledR}$ Typer software.

\section{Data analysis}

Twenty-five karyotypically confirmed euploid amniocyte culture samples were used to generate a set of reference control data, to which all later cases could be compared. These samples were run in duplicate and in two separate runs using the method described above. Data from the sample analyses were transferred to a Microsoft ${ }^{\circledR}$ Excel spreadsheet. From this set of data, inherent biases in the individual assay reactions could be identified, and a skew correction factor for each assay was generated by the MassARRAY® Typer software using the "Genotype Area" report feature of the program. All experiments following this were corrected for assay bias using these skew correction factors and the "Allelotype Correction" report feature of the MassARRAY ${ }^{\circledR}$ Typer software.

From the 25 reference control samples, the average allelic ratio and the standard deviations for each of the 11 SNP assays were calculated. Logarithmic values of the skew-corrected peak areas from the mass spectra were used to improve the linearity of these values and all other samples later in this study. The skew correction values were used to adjust for allele-specific preferences during the amplification, extension and mass spectrometric steps. These reference control ratios and standard deviation values were then used for subsequent comparison and calculation of the test samples' probability of being normal or abnormal with regard to chromosome 21 number.

For each test sample, the ratio of the low mass allele relative to the high mass allele for each assay demonstrating heterozygosity was calculated using skew-corrected, logarithmic values of the allele frequencies. These ratios were compared to the reference control ratios, with expected allelic ratios of the trisomic samples being ideally either 0.5 or 2.0. Because of the unequal weight of some of the ratios relative to the average normal ratio (i.e., 0.5 is closer to 1 than 2 is to 1 ), the inverse of all ratios $<1.0$ were taken. For each informative assay, that is, those demonstrating the presence of a heterozygous SNP, the number of standard deviations the observed peak allelic ratio was away from the reference control ratio was first calculated using the equation:
Standard Deviations Away from Control Ratio

$$
=\frac{\text { Observed Ratio }- \text { Reference Control Ratio }}{\text { Reference Standard Deviation for Assay }}
$$

The standard deviations for all informative assays of that particular sample were then averaged:

Average Standard Deviations From Control Ratios

$$
=\frac{\sum \text { Standard Deviations }}{\text { Number of Informative Assays }}
$$

\section{Ratios (ASD)}

The average number of standard deviations away from the reference control ratios (ASD), in combination with the number of informative SNPs present, determined the probability of a sample being affected or unaffected. Each sample analyzed in this study was assigned to one of six categories using an analytical algorithm (Table 3 ). The data were analyzed separately by type of sample, and subsequently as a combined data set.

\section{RESULTS}

The allelic ratios for each assay for the reference control data set all equaled approximately 1 (range $0.96-1.17$ ), as anticipated for euploid samples, with the standard deviations for the assays ranging from 0.17 to 0.26 . After establishment of this reference control data set, blinded samples were then evaluated for chromosome 21 number by comparing the allelic ratios determined from MALDI-TOF mass spectrometry to the reference control ratios for each informative SNP.

Known trisomy 21 and euploid samples were analyzed and compared to the reference control data in order to test the method. DNA from 7 trisomic amniocyte cell cultures and 12 euploid cultures were evaluated, revealing a clear distinction between trisomic and euploid samples (Table 4, Fig. 1). The average ASD value for the known euploid samples was 1.01 (range 0.502.14), while that for the trisomic samples was significantly higher at 6.33 (range 5.40-7.60). All trisomic samples were identified as

Table 3

Analytical algorithm for determining a sample's probability of being trisomic or non-trisomic with regard to chromosome 21

\begin{tabular}{lcl}
\hline ASD Value $^{a}$ & $\begin{array}{c}\text { Number of } \\
\text { Informative Assays }^{b}\end{array}$ & \multicolumn{1}{c}{ Call } \\
\hline N/A & 0 & Uninformative \\
$\leq 3$ & $>2$ & Unaffected \\
$\leq 3$ & $1-2$ & Probable unaffected \\
$3-4$ & $>0$ & Probable unaffected \\
$\geq 4$ & $1-2$ & Possible affected \\
$4-5$ & $>2$ & Probable affected \\
$\geq 5$ & $>2$ & Affected \\
\hline
\end{tabular}

${ }^{a}$ ASD, average number of standard deviations away from reference control peak ratios.

${ }^{b}$ an assay in which the SNP was found to be present in the heterozygous state. 
Table 4

Results categorized by sample type and chromosome 21 status

\begin{tabular}{|c|c|c|c|c|c|c|c|}
\hline Sample Type & Total n & $\begin{array}{l}\text { Chromosome } \\
21 \text { Status }\end{array}$ & $\mathrm{n}$ & $\begin{array}{l}\text { Average Number of } \\
\text { Informative } \mathrm{SNPs}^{a}\end{array}$ & Range & $\begin{array}{l}\text { Average } \\
\mathrm{ASD}^{b}\end{array}$ & Range \\
\hline \multirow[t]{2}{*}{ Unblinded amniocyte cultures } & 19 & Non-trisomic & 12 & 5.25 & $3-8$ & 1.01 & $0.50-2.14$ \\
\hline & & Trisomic & 7 & 7.43 & $4-9$ & 6.33 & $5.40-7.60$ \\
\hline \multirow[t]{2}{*}{ Amniotic fluid (uncultured) } & 120 & Non-trisomic & 93 & 5.26 & $1-11$ & 0.89 & $0.40-3.75$ \\
\hline & & Trisomic & 27 & 7.15 & $3-11$ & 7.20 & $5.28-9.56$ \\
\hline \multirow[t]{2}{*}{ Amniocyte cultures } & 40 & Non-trisomic & 3 & 4.00 & $3-5$ & 1.22 & $0.58-1.87$ \\
\hline & & Trisomic & 37 & 8.00 & $4-11$ & 6.40 & $4.66-8.16$ \\
\hline \multirow[t]{2}{*}{ Chorionic villus samples } & 115 & Non-trisomic & 110 & 4.62 & $1-9$ & 0.69 & $0.03-2.71$ \\
\hline & & Trisomic & 5 & 7.20 & $5-9$ & 6.20 & $4.80-7.30$ \\
\hline \multirow[t]{3}{*}{ Amniotic fluid supernatants } & 75 & Non-trisomic & 70 & 5.30 & $1-10$ & 0.98 & $0.05-3.59$ \\
\hline & & Trisomic & 4 & 7.00 & $7-7$ & 6.64 & $5.00-7.37$ \\
\hline & & Mosaic & 1 & 7.00 & N/A & 0.68 & N/A \\
\hline \multirow{2}{*}{$\begin{array}{l}\text { All blinded samples (excluding } \\
\text { mosaic sample) }\end{array}$} & 349 & Non-trisomic & 276 & 5.00 & $1-11$ & 0.84 & $0.03-3.75$ \\
\hline & & Trisomic & 73 & 7.58 & $3-11$ & 6.69 & $4.66-9.56$ \\
\hline
\end{tabular}

${ }^{a}$ Average number of informative (heterozygous) SNPs for all samples in group.

${ }^{b}$ ASD, Average number of standard deviations away from the reference control ratios; values in column indicate averaged ASDs for all samples in group.

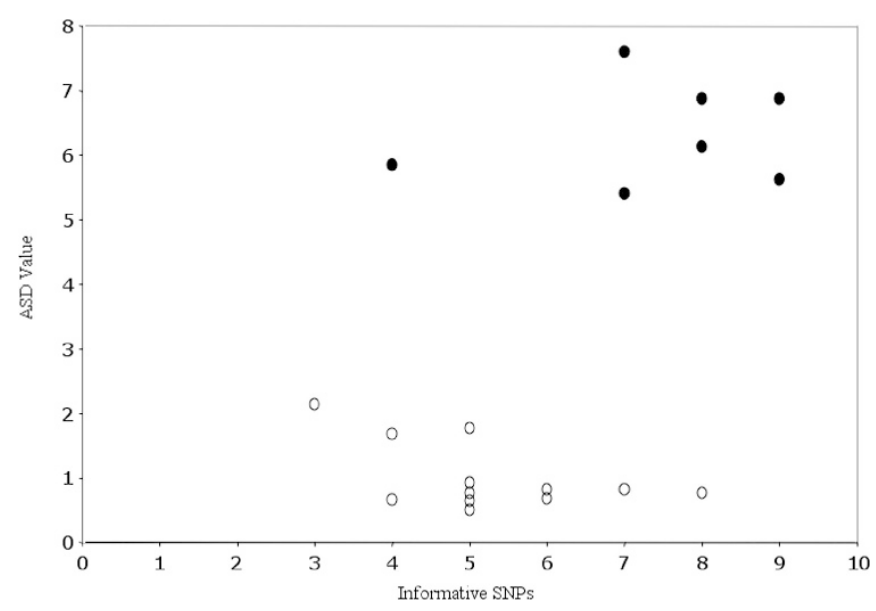

Fig. 1 Average number of standard deviations away from the reference control ratios plotted against the number of informative SNPs per sample for known euploid and trisomy 21 amniocyte cultures. Average number of standard deviations away from the reference control ratios for all informative (heterozygous) assays is shown on the Y-axis. The number of informative SNPs per sample is indicated on the X-axis. Solid black circles indicate trisomy 21 samples. Clear circles indicate euploid samples. ASD, average number of standard deviations away from reference control ratio; SNP, single nucleotide polymorphism.

"affected," while all the euploid samples fell into the category of "unaffected."

Following this successful trial, the blinded analysis was performed and the results were checked after completion of all analyses against karyotype results. The results are summarized in Table 4. In this study, 73/350 (20.9\%) samples analyzed were trisomy 21. The ASD values of the trisomy cases were higher than those of the euploid samples, and this distinction can be clearly seen when the ASD values were plotted against the number of informative SNPs for each sample (Fig. 2). Seventy- one of the 73 trisomy 21 samples (97.3\%) had an ASD value of at least 5.00, placing them in the affected category based on the analytical algorithm; this included $27 / 120$ crude amniotic fluid samples (Fig. 2A), 36/40 amniocyte cultures (Fig. 2B), 4/115 chorionic villus samples (Fig. 2C), and 4/75 amniotic fluid supernatant samples (Fig. 2D). Only two trisomy 21 cases (2.7\%) having ASD values falling between 4.00 and 5.00 ( 1 amniocyte culture sample with ASD value 4.66, and 1 chorionic villus sample with ASD value 4.80) were categorized as probable affected based on the algorithm.

There were 276 nontrisomy 21 samples present among the blinded samples analyzed, and these included not only euploid samples, but also a number of other chromosomally abnormal samples such as trisomy 13 , trisomy 18 , and several translocations and inversions not involving chromosome 21. Two hundred fifty of these $(90.6 \%)$ could be categorized as unaffected with regard to chromosome 21 number based on the algorithm, with the remaining 26 samples (9.4\%) categorized as probable unaffected. The average ASD for all nontrisomy 21 samples was 0.84 (range 0.03-3.75), while that for the trisomy 21 samples was clearly higher at $6.69(4.66-9.56)$. No samples fell into the least certain category of possible affected. However, a single amniotic fluid supernatant sample exhibiting mosaicism for trisomy 21 (47, XX + 21[5] 46, XX[21]) had an ASD value of 0.68 and was not identified as being abnormal with regard to chromosome 21 number.

As predicted from the analysis of 11 SNPs, $98.6 \%$ (345 samples) of the entire sample set had 2 or more informative SNPs. No samples were completely uninformative, that is, all had at least one heterozygous SNP. Notably, euploid samples had on average fewer informative SNPs than trisomic samples, as indicated in 

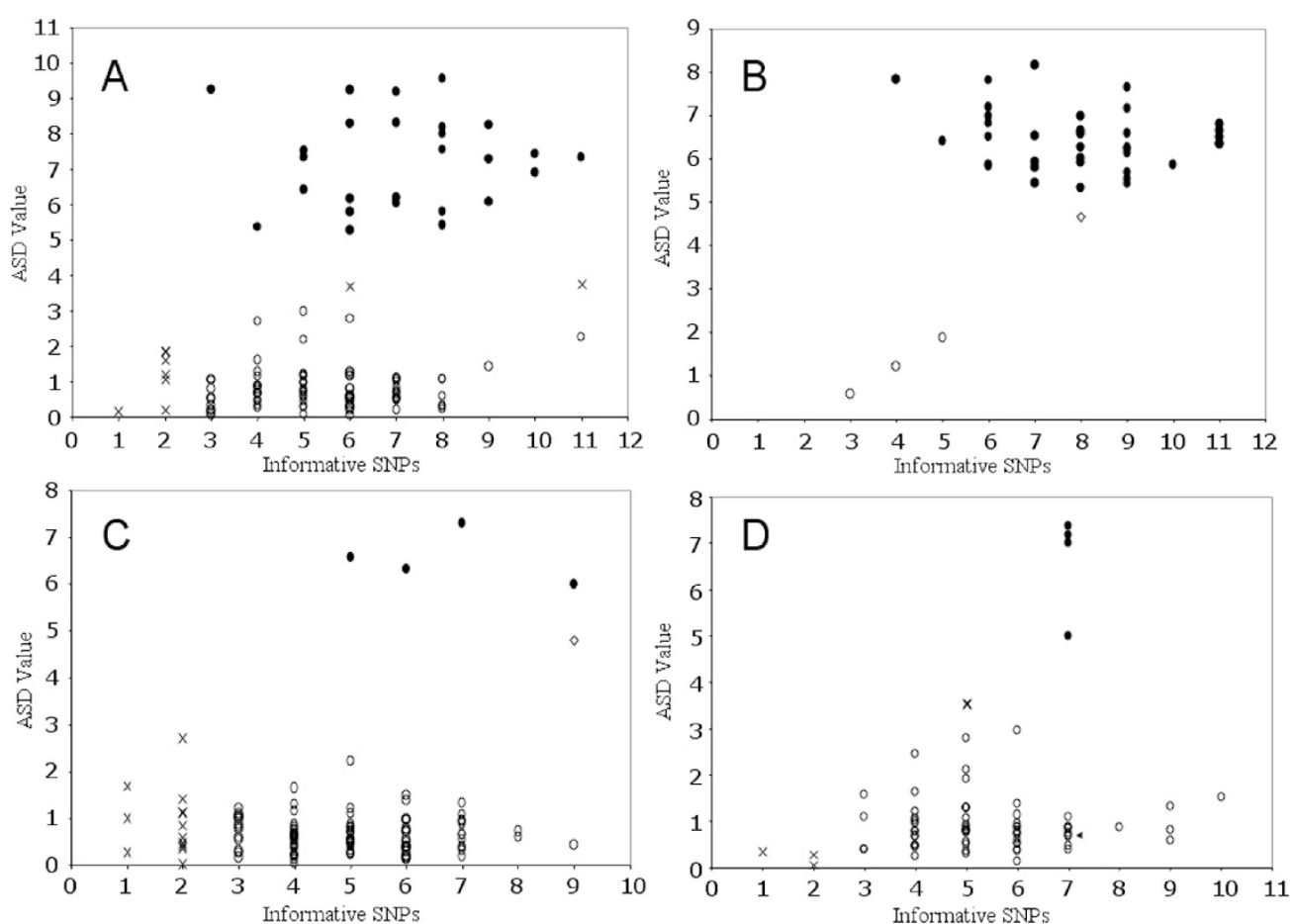

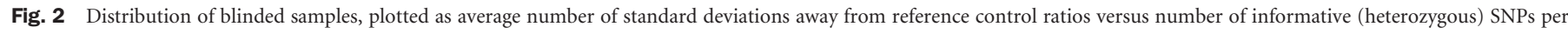

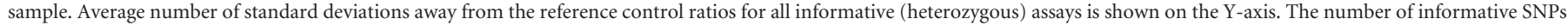

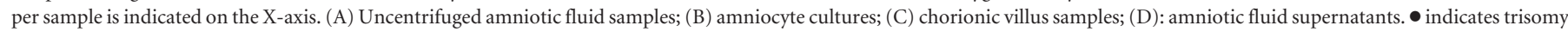

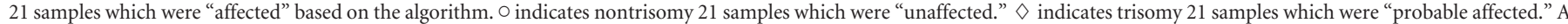

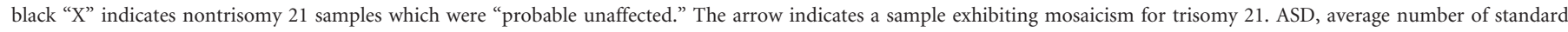
deviations away from reference control ratio; SNP, single nucleotide polymorphism.

Table 4 and also clearly observable in Figures 1 and 2. The euploid samples had an average of 5.00 informative SNPs (range 1-11), and 23 of these $(8.3 \%$ ) had only 1 or 2 informative SNPs. In contrast, trisomy 21 samples had an average of 7.58 informative SNPs (range 3-11), and none of these had $<3$ informative SNPs. This difference may have contributed to the increased number of probable unaffected calls within the nontrisomy 21 samples. Furthermore, this observation may be attributed to the fact that most cases of trisomy 21 are of maternal origin and arise from nondisjunction during meiosis I, rather than from nondisjunction during meiosis II, which would result in two identical chromosomes of maternal origin..$^{21,22}$

\section{DISCUSSION}

In our study, we demonstrated that MALDI-TOF mass spectrometric analysis of SNPs is a robust and reproducible technique for detection of trisomy 21 in clinical samples of fetal origin. We showed that it can be used with a variety of sample types, including amniotic fluid supernatant. MALDI-TOF mass spectrometric analysis of this cell-free DNA-rich material, normally discarded after removal of cells for karyotyping, could be particularly useful in cases where cell cultures fail and karyotyping cannot be performed.

Compared to karyotyping, MALDI-TOF mass spectrometric analysis has the advantage of having a faster time to result, with the ability to obtain results within two days, compared to an up to two-week waiting period with karyotyping. In addition, it is very amenable to high-throughput analysis, with the possibility currently of evaluating up to 384 samples on a single chip. Furthermore, it has the advantage of not requiring intact cells for analysis. At present, the assays examined here are only for the detection of trisomy 21, but development of assays for other aneuploidies would make this an even more useful technique.

To consider such a technique as the one described here as a plausible mainstream diagnostic tool, it must be taken into account that the more heterozygous SNPs available for analysis in any given sample, the more definitive the diagnosis will be. Analysis of 11 SNPs in this study resulted in an approximately 99\% chance of finding at least two heterozygous SNPs and a nearly $95 \%$ chance of having at least three heterozygous SNPs. Increasing the number of SNPs evaluated would further improve the certainty of the calls.

Also of importance in the development of a potential diagnostic tool is the implementation of a simple and reliable method for evaluating test results. We demonstrated in our study that MALDI-TOF mass spectrometry could be combined with an analytic algorithm for easily identifying a sample's probability of being trisomy 21 or euploid. This algorithm was developed as a demonstrative method, rather than as an actual clinical tool, and thus would not be useful at present for such a diagnostic purpose. However, further studies involving a much larger number of samples across various labs could be performed to validate and refine this method, and importantly, to assign a numerical value to each 
diagnostic category, such that if it were to be used in a real clinical situation, the patient could be informed of the actual risk of having an affected fetus.

Analyzing fetal allele status with MALDI-TOF mass spectrometry, like other PCR-based methods, is prone to contamination with maternal blood and cells. A high enough amount of contamination could alter the allelic ratios and result in false negative results, although this was not observed among the 350 samples examined in this study. Along similar lines, in cases of mosaicism where only a certain proportion of cells may be trisomic, the allele status may be missed, resulting in a false negative result, as demonstrated by the single mosaic case in our study. This is one particular disadvantage compared to FISH and karyotyping, whereby looking at individual cells, mosaicism can be readily identified and the extent of the mosaicism determined.

The genetic variability across different ethnic populations is another important consideration. SNPs are extremely common in the human genome, with approximately one SNP per kilobase. ${ }^{15}$ The frequencies at which they are found make them ideal for molecular mapping and fine-tailoring assays to evaluate genes or portions of genes of interest. However, these markers must be present in a heterozygous state to be useful for determining chromosome number, and the degree of heterozygosity of SNPs can vary greatly among different ethnic populations. Thus, a set of assays optimized for diagnosis in one ethnic group (as in our case, for a Caucasian population) may not perform as well in others. In cases where the subjects are of diverse ethnic backgrounds, great care would be needed to select a combination of assays that would provide sufficient diagnostic sensitivity regardless of ethnic background.

It is clear that further work needs to be performed before MALDI-TOF mass spectrometry can be considered as a prenatal diagnostic tool, possibly complementary to karyotyping or as an alternative to FISH or QF-PCR. One eventual goal would be to apply this technology to noninvasive prenatal diagnosis using maternal blood to detect fetal aneuploidies. It remains to be seen how well this technique can be applied for this purpose, due to the presence of both maternal and fetal species in the maternal circulation. Another important question regards how well MALDI-TOF mass spectrometry can compete with other molecular methods of chromosome analysis, particularly array $\mathrm{CGH}$, in this rapidly evolving field. Nevertheless, we have demonstrated in this study that MALDI-TOF mass spectrometry is an accurate and reproducible method for the determination of trisomy 21 status from a wide variety of clinical samples of fetal origin. Additionally, the application of an algorithm such as the one used in this study could help standardize interpretation of sample analyses for potential future clinical usage.

\section{ACKNOWLEDGMENTS}

We thank Sequenom, Inc. (San Diego, California) and Dr. Andreas Braun for loan of the MassARRAY ${ }^{\circledR}$ Compact system and support for this project. On behalf of Sequenom, Inc., we thank Dr. Aubrey Milunsky for provision of valuable samples for the initial analyses. We also thank Dr. Susanne Müller for her extensive technical assistance, and Drs. Carolyn Wrightson, Anurag Gupta, Ying Li and Corinne Rusterholz for their suggestions and critical readings of the manuscript. This work was supported by the SAFE Network of Excellence, project number LSHB-CT-2004-503243 and by the Polish Committee for Scientific Research, grant number 3-PO5E-156-22.

\section{References}

1. Gardner RJM, Sutherland GR. Pregnancy loss and infertility. In: Chromosome Abnormalities and Genetic Counseling. New York: Oxford University Press, 1996;311-321.

2. Korenberg JR, Chen XN, Schipper R, Sun Z, et al. Down syndrome phenotypes: the consequences of chromosomal imbalance. Proc Natl Acad Sci U S A 1994;91:4997-5001.

3. Gardner RJM, Sutherland GR. Prenatal diagnostic procedures. In: Chromosome Abnormalities and Genetic Counseling, 2nd ed. New York: Oxford University Press, 1996;336-344.

4. Rhoads GG, Jackson LG, Schlesselman SE, de la Cruz FF, et al. The safety and efficacy of chorionic villus sampling for early prenatal diagnosis of cytogenetic abnormalities. N Engl J Med 1989;320:609-617.

5. Dudarewicz L, Holzgreve W, Jeziorowska A, Jakubowski L, et al. Molecular methods for rapid detection of aneuploidy. J Applied Genet 2005;46:207-215.

6. Van den Veyver IB, Beaudet AL. Comparative genomic hybridization and prenatal diagnosis. Curr Opin Obstet Gynecol 2006;18:185-191.

7. Larrabee PB, Johnson KL, Pestova E, Lucas M, et al. Microarray analysis of cell-free fetal DNA in amniotic fluid: a prenatal molecular karyotype. Am J Hum Genet 2004;75:485-491.

8. Miura S, Miura K, Masuzaki H, Miyake N, et al. Microarray comparative genomic hybridization (CGH)-based prenatal diagnosis for chromosome abnormalities using cell-free fetal DNA in amniotic fluid. J Hum Genet 2006;51:412-417.

9. Le Caignec C, Spits C, Sermon K, De Rycke M, et al. Single-cell chromosomal imbalances detection by array CGH. Nucleic Acids Research 2006;34:E68.

10. Verma L, Macdonald F, Leedham P, McConachie M, et al. Rapid and simple prenatal DNA diagnosis of Down's syndrome. Lancet 1998;352:9-12.

11. Findlay I, Toth T, Matthews P, Marton T, et al. Rapid trisomy diagnosis (21, 18, and 13) using fluorescent PCR and short tandem repeats: applications for prenatal dIagnosis and preimplantation genetic diagnosis. J Assist Reprod Genet 1998;15:266-275.

12. Levett LJ, Liddle S, Meredith R. A large-scale evaluation of amnio-PCR for the rapid prenatal diagnosis of fetal trisomy. Ultrasound Obstet Gynecol 2001;17:115-118.

13. Mansfield ES. Diagnosis of Down syndrome and other aneuploidies using quantitative polymerase chain reaction and small tandem repeat polymorphisms. Human Mol Genet 1993;2:43-50.

14. Pertl B, Kopp S, Kroisel PM, Hausler M, et al. Quantitative fluorescence polymerase chain reaction for the rapid prenatal detection of common aneuoploidies and fetal sex. Am J Obstet Gynecol 1997;117:899-906.

15. Wang DG, Fan JB, Siao CJ, Berno A, et al. Large-scale identification, mapping, and genotyping of single-nucleotide polymorphisms in the human genome. Science 1998;280:1077-1082.

16. Pont-Kingdon G, Lyon E. Rapid detection of aneuploidy (trisomy 21) by allele quantification combined with melting curves analysis of single-nucleotide polymorphism loci. Clin Chem 2003;49:1087-1094.

17. Nagy B, Ban Z, Lazar L, Nagy RG, et al. Rapid determination of trisomy 21 from amniotic fluid cells using single-nucleotide polymorphic loci. Prenat Diagn 2005;25: 1138-1141.

18. Oeth P, Beaulieu M, Park C, Kosman D, et al. iPLEX Assay: Increased Plexing Efficiency and Flexibility for MassARRAY System Through Single Base Primer Extension with Mass-Modified Terminators. Sequenom application note, 2005.

19. Nelson MR, Whitacre JL, Oeth P, Kammerer S, et al. Rapid diagnostic test for trisomy 21 and other aneuploidies using mass spectrometry. ACMG. Chicago, June 3-5, 2005.

20. Tsui NBY, Chiu RWK, Ding C, El-Sheikhah A, et al. Detection of trisomy 21 by quantitative mass spectrometric analysis of single-nucleotide polymorphisms. Clin Chem 2005;51:2358-2362.

21. Juberg RC, Mowrey PN. Origin of nondisjunction in trisomy 21 syndrome: all studies compiled, parental age analysis, and international comparisons. Am J Med Genet 1983;16:111-116.

22. Nicolaidis P, Petersen MB. Origin and mechanisms of non-disjunction in human autosomal trisomies. Human Reprod 1998;13:313-319. 